Meta

Journal des traducteurs

Translators' Journal

\title{
Technologies, Discourse Analysis, and the Spoken Word: The MRC Approach: An Empirical Approach to Interpreter Performance Evaluation and Pedagogy
}

\section{Peter P. Lindquist}

Volume 50, numéro 4, décembre 2005

Pour une traductologie proactive - Actes

For a Proactive Translatology — Proceedings

Por una traductología proactiva - Actas

URI : https://id.erudit.org/iderudit/019848ar

DOI : https://doi.org/10.7202/019848ar

Aller au sommaire du numéro

Éditeur(s)

Les Presses de l'Université de Montréal

ISSN

0026-0452 (imprimé)

1492-1421 (numérique)

Découvrir la revue

Citer cet article

Lindquist, P. P. (2005). Technologies, Discourse Analysis, and the Spoken Word: The MRC Approach: An Empirical Approach to Interpreter Performance

Evaluation and Pedagogy. Meta, 50(4). https://doi.org/10.7202/019848ar

\section{Résumé de l'article}

La parole étant évanescente, les interprètes sont évalués, formés et choisis en s'appuyant sur des bases théoriques non prouvées et sur des préconceptions des processus cognitifs et des secteurs de difficultés liées au travail. Un fossé existe entre les travaux théoriques et l'évidence empirique des processus proposés par de telles études. De récents développements technologiques utilisés à présent pour l'évaluation de la performance des interprètes apporte des informations sur certains aspects de la performance des interprètes inanalysables auparavant. Il est à présent possible d'analyser d'importantes quantité de " parole » à la fois auditives et textuelles. Cet article présente le modèle MRC d'analyse de la performance des interprètes et une étude avec cette méthode dans le but de déterminer les besoins de formation des interprètes. On donne également l'histoire théorique du modèle $\mathrm{MRC}$, ainsi que les conclusions et implications pédagogiques. 


\title{
Technologies, Discourse Analysis, and the Spoken Word: The MRC Approach: An Empirical Approach to Interpreter Performance Evaluation and Pedagogy
}

\author{
PETER P. LINDQUIST \\ University of Arizona,Tucson, USA \\ ppl@u.arizona.edu
}

\begin{abstract}
RÉSUMÉ
La parole étant évanescente, les interprètes sont évalués, formés et choisis en s'appuyant sur des bases théoriques non prouvées et sur des préconceptions des processus cognitifs et des secteurs de difficultés liées au travail. Un fossé existe entre les travaux théoriques et l'évidence empirique des processus proposés par de telles études. De récents développements technologiques utilisés à présent pour l'évaluation de la performance des interprètes apporte des informations sur certains aspects de la performance des interprètes inanalysables auparavant. Il est à présent possible d'analyser d'importantes quantité de « parole » à la fois auditives et textuelles. Cet article présente le modèle MRC d'analyse de la performance des interprètes et une étude avec cette méthode dans le but de déterminer les besoins de formation des interprètes. On donne également l'histoire théorique du modèle MRC, ainsi que les conclusions et implications pédagogiques.
\end{abstract}

\begin{abstract}
Given the evanescent quality of the spoken word, interpreters tend to be evaluated, trained, and selected on the basis of unproven theories and preconceptions about the cognitive processes and areas of difficulty associated with their work. A gap persists between theoretical work and empirical evidence of the processes proposed by such studies. Recent developments in technology are now being applied to interpreter performance evaluation, shedding light on aspects of interpreter performance that have previously resisted systematic analysis. It is now possible to examine large volumes of language in use, in both audio and textual realms. This paper presents the MRC model for analysis of interpreter performance and a study conducted using that method for the purpose of identifying interpreter training needs. Theoretical background, the MRC model, and the study outcomes and pedagogical implications are presented.
\end{abstract}

MOTS-CLÉS/KEYWORDS

discourse analysis, corpus linguistics, audio corpora, interpreting, empirical studies

\section{Introduction}

The completeness and accuracy of interpreters' and translators' work profoundly impact all stakeholders in language-mediated events. In spite of the high stakes, the means by which interpreters are trained and selected are often based on preconceptions and anecdotal evidence of interpreter performance, rather than on empirical evidence. Language in use is resistant to objective study; the work of translators and interpreters is even more so. Variability of expression, or the nearly infinite number of ways that an idea may be expressed makes it difficult to establish one-toone correspondences between elements of a source-text (ST) message and their target-text (TT) counterparts. In translation and interpreting, messages must often be adapted, either grammatically or culturally in order to make sense in the target language, to meet the expectations of the targetlanguage receiver, and to convey the impact of the original message. This adaptation or modulation of the message complicates the notion of ST/TT equivalence. The study of interpreting, or translation of the spoken word, is further complicated by paralinguistic factors such as hesitations, false-starts, vocal inflection, and tone of voice, all of which affect the conveyance of a message. 
This is not to say that meaningful studies of translation and interpreting have not been conducted, but that the theories and hypotheses resulting from such work have been difficult to test on the basis of empirical data. Advances in technology have begun to break this theoretical/empirical gridlock. It is now possible to examine large amounts of language in use, whether in textual or audio format, to begin to confirm or refute existing theories and hypotheses. The model for interpreter performance assessment presented here applies digital audio, word-processing, and spreadsheet technologies to a study which combines discourse analysis and corpus linguistics techniques in order to improve interpreter training by identifying specific areas of difficulty for student interpreters.

Translation, whether of text or the spoken word involves cognitive processes and skills which are different from those involved in monolingual communication. Neubert (1997: 23-4) Interpreting involves cognitive processes and skills which are also different from those involved in translation. Interpreting is different from text translation with respect to time: interpreters must begin to render a text before it has been fully expressed, must keep up with the ST speaker, and cannot usually consult reference materials during the interpreting process. As a consequence of these time factors, simultaneous interpreting involves multiple, often competing cognitive processes as the interpreter listens to the source material, comprehends it, then renders it in the target language while listening to the next portion of the ST message. Additionally, interpreters are expected to reconvey ST content, rather than its form; this not only permits, but requires considerable restructuring or modulation. Seleskovitch (1976: 93) Our understanding of monolingual communication and translation has been informed by work done in Speech Act, Discourse Analysis, Skopos, and Pragmatics theories, and more recently, Corpus Linguistics. [cf: Searle (1975), Toury (1995), Reiss \& Vermeer (1984), Sinclair (1991), Stubbs (1996), Biber (1998)] However, the time-related factors and questions of cognitive load management of interpreting are not considered in those theory sets. A number of plausible models have been developed to explain the cognitive processes involved in interpreting, but because those processes are not directly observable, they can only be tested using secondary indicators. [cf. Gerver (1976), Gile (1994, 1997), Moser-Mercer $(1977,1997)]$ It is now becoming possible to apply analytical tools which have proven useful in translation studies to the spoken word and begin to confirm or refute theories of interpreter process and product.

\section{Study goals and criteria}

1. Minimize effects of preconceptions: To improve interpreter training by identifying areas of difficulty through the examination of empirical evidence of interpreter performance in such a way that the analyst's preconceptions and biases exert minimum influence on the findings.

2. Consider paralinguistic features: To construct an analytical model which would permit the examination of spoken discourse in such a way that both linguistic and extra-linguistic aspects of interpreter performance could be observed and analyzed.

3. Cognitive processes: To gain insight into the cognitive processes involved in simultaneous interpreting by examining shifts and/or errors within the context of existing cognitive-process models.

4. Language-neutrality: The model shall be language-neutral so that it may be applied to any language pair.

5. Flexibility: The model shall be easily adaptable to a broad variety of query types.

6. Micro/macro view of discourse: The model shall permit the consideration of elements of speech at all levels, from the word or phrase level to sentence, paragraph or whole-text levels (micro/macro views of discourse).

\section{Obstacles}

1. Parallel corpora consisting of multiple interpreter renderings of identical source texts were not available. 
2. Short term memory for audio information is limited, posing a significant obstacle to the researcher when comparing multiple audio recordings of TT renderings.

3. Due to the need to restructure ST elements in the TT, one-to-one correspondences of ST and TT elements may be difficult, and in some cases, impossible to establish.

4. The criteria for assessing interpreter performance are not universally established and the term "quality" is not objectively defined.

5. The quantity of information in the corpora to be analyzed and the observations made during analysis of those corpora present significant structural and organizational challenges.

\section{Meeting goals and criteria}

1. Minimize effects of preconceptions: In Corpus Linguistics, large amounts of real language are examined, usually using computer assisted methods. Frequency counts of linguistic phenomena are performed on these corpora, allowing researchers the benefit of examining linguistic elements in context. This approach has been adapted here for use with spoken language, using a parallel corpus consisting of two short speeches and multiple renderings of each. Both speeches were drawn from real conferences. One speech was given in English and rendered into Spanish, and the other was given in Spanish and rendered into English. Audio recordings were made of forty studentinterpreter renderings of each speech. The audio recordings were transcribed and all hesitations, false-starts, pauses and disfluencies were approximately represented in the audio recordings. These renderings were compared to the ST. Observations were made based on universal features of communication: the extent to which the meaning, rhetorical value, and clarity of the source message were conserved and the mechanics, such as omission, addition, grammatical, syntactic, or lexical shifts by which any deviations occurred. These features will be described more fully below. 2. Paralinguistic features: The goal of examining both linguistic and paralinguistic elements was met by examining both the audio and textual versions of each rendering. A cross-referencing system, described later, made it possible to quickly and easily compare the audio recordings and their transcripts and to efficiently compare the various renderings of any given portion of text. For the purposes of this discussion, "text" refers to both the spoken word and its textual transcription. 3. Cognitive processes: Errors and shifts are considered in light of prevailing theories about the cognitive processes involved in simultaneous interpreting. Correlations between certain error distributions and phenomena such as delayed and cascading errors and of self-monitoring and correction may be used to confirm or refute theories describing their presumed causes.

4. Language-neutrality: The criterion of language-neutrality is met by using universal features of language and communication, rather than language-specific factors as the basis for the study. All communicative events may be considered in terms of meaning, rhetorical value, and clarity of expression. In terms of mechanics, universal features, such as omissions, additions, lexical choices, grammar, syntax, fluency, pronunciation, and intelligibility are used.

5. Flexibility: The model is structured to accommodate various types of query. The binomial effect/mechanics coding system used in the original study and presented here represents only one query type. If for example, one wanted to examine linguistic or phonetic interference in the corpora, the coding system, spreadsheet, and tallying mechanisms could be easily adapted to consider those issues without altering the overall structure of the study model. There are no preset limits to the number of variables that may be tracked.

6. Micro/macro view of discourse: The architecture of the model permits the analyst to consider elements of speech of any size, from single phonemes to full-text. Discourse Analysis considers each utterance in relation to the portion of text in which it appears, as well as the overall message and intent of the ST. The context in which elements appear, as well as the situation in which the discourse takes place are taken into account. This does not in any way prevent close examination of linguistic details of individual elements of each performance. 


\section{Solutions to obstacles}

1. Parallel corpora: A parallel corpus of approximately 80,000 words was developed for this study. Forty TT renderings of two speeches were compiled.

2. Short term memory for audio: The audio recordings were transferred to a computer-based audio recording system which allowed all of the TT recordings to be placed on a single "page" on the computer screen, allowing both visual reference for the recordings and efficient switching of audio tracks.

3. Objective criteria for analysis: The criteria by which adequacy in interpreting is assessed in this study are derived from widely accepted standards of translation and from studies in which interpreters, those who contract for their services, and TT receivers identified the issues which they considered most important to effective interpreting. The factors considered to be of critical importance to those surveyed in these studies were: that the TT make sense, that terminology be used correctly, and that it require a minimum of additional decoding by the TT receiver. (ColladosAís 1999; Kopczynski 1994) Accepted standards of adequacy in translation, and by extension interpreting, as summarized by Eugene Nida indicate that the target text must: make sense, convey the "spirit and manner of the original," and must produce a response in the TT receiver similar to that of the ST receiver. Nida (1964: 164) The categories established for evaluating re-conveyance of the ST message are derived from a synthesis of the criteria described in the surveys cited above and these standards of adequacy, resulting in the broad message-content categories of: meaning, rhetorical value, and clarity.

4. Modulation and restructuring of TT: Because elements of TT renderings often do not have easily identified one-to-one correspondence with their ST counterparts, the source texts were correlated with the target texts using a combination of numbered phrases and time-codes. The ST was divided into small word-groupings which were numbered for identification and location purposes and correlated with the time-codes in the TT renderings.

5. Quantity of information: ST and TT audio recordings were time-aligned and the transcriptions were labeled with time codes at fifteen second intervals. Using the "find word" function in the word processing program, it is possible to perform semi-automated searches of the corpus by entering time codes, words or word fragments, and/or the numbers assigned to ST elements into the "find word" dialogue box. The observations were recorded and tracked in spreadsheet format, using Microsoft Excel. An application was developed in which the ST could be transcribed onto

the spreadsheet and observations entered in a binomial code below the relevant word or phrase. The spreadsheet application automatically generates frequency counts of the binomial codes which are shown in separate tables.

\section{Study structure}

The study for which the MRC model was developed is based on a dual corpus consisting of two source texts and 40 target texts of each. It bears repeating that for the purposes of this discussion, the term "text" is used in its most generic sense and refers to either the spoken or written form of discourse. The corpus consists of audio recordings and transcriptions of each student rendering and source text. One source text, in Spanish consists of a reenactment of an actual conference presentation about the integration of handicapped children in the school system in Spain which was presented to the students by their professor, a fluent, but non-native Spanish-speaker. The other source text, given in English was delivered by the same speaker, whose dominant language is English. Also a reenactment of an actual conference presentation, this text discusses youth participation in the European Union. The speech is presented in a style consistent with conference presentations of its type, including a combination of prepared and improvised utterances. The source texts include well-formed sentences as well as false starts, hedges and other components of extemporaneous speech. The rate of speech is approximately 120 words per minute. Each presentation is given in a formal register, with minimal technical language. The technical language present consists of terminology associated with educational and socio-political discussion. Few numbers are recited and no processing of those numbers is required of the interpreter. 


\section{Sample population}

All student interpreters are native speakers of Spanish and all had acquired English in an academic setting. Students possessed varying degrees of proficiency in English, and an unspecified number had studied in English-speaking countries as part of exchange programs. All student interpreters were in their final year of an undergraduate course of study in Translation and Interpreting. Students had completed 180 hours of interpreting instruction, of which 90 hours were dedicated to the simultaneous mode.

\section{Sample gathering}

All recordings were made simultaneously in the same location under identical conditions. Each student worked in a separate audio booth in which the source text was heard through headsets of the same make and model, typical of those used by interpreters in conference situations, connected to identical language-laboratory equipment. Student renderings were recorded on analog audio cassette recorders located in each booth.

\section{Methodology}

Audio: The recordings were transferred to a computer-based digital multi-track recording program called "Cakewalk" by Sonus. Each interpreter performance was placed on adjacent tracks. The software provided a visual representation of each recording, as well as the ability to quickly switch from one rendering to another during playback. (Figure 1) Precise time codes are accessible for all tracks at all times, permitting measurement of lag times between ST utterances and TT renderings. The time codes also make it possible to efficiently correlate TT utterances within the audio portion of the corpus and their textual counterparts in both the ST and TT. 


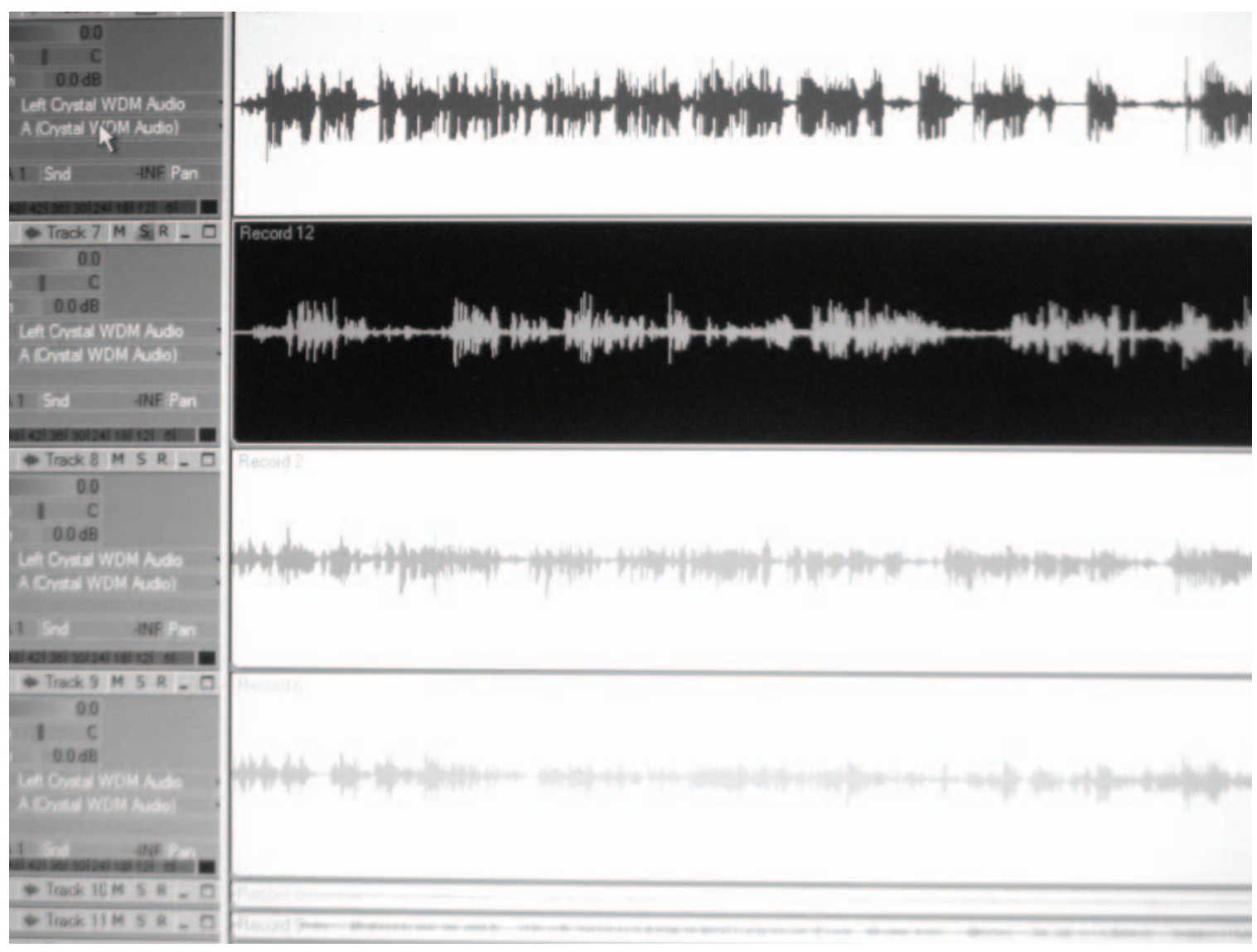

Figure 1. Visual representation of audio recordings of interpreter renderings

\section{Transcriptions}

All recordings were transcribed with hesitations, false-starts, and other disfluencies annotated. As mentioned above, the ST was "chunked" or divided into sequentially numbered small word groupings. The numbering system was used as an aid to semi-automated searches of the ST. Also, in cases where a term appears various times in the ST, each use may be distinguished by its numerical label. The ST was marked with time codes at fifteen second intervals. (Figure 2) The target text transcriptions were merged and time codes entered at fifteen second intervals. The time codes allow TT utterances to be identified with their ST counterparts, regardless of the extent to which they may be restructured. Time codes, numbered "chunks," words, and word fragments may be located using the "find word" function of the word processing program. (Figure 3) 


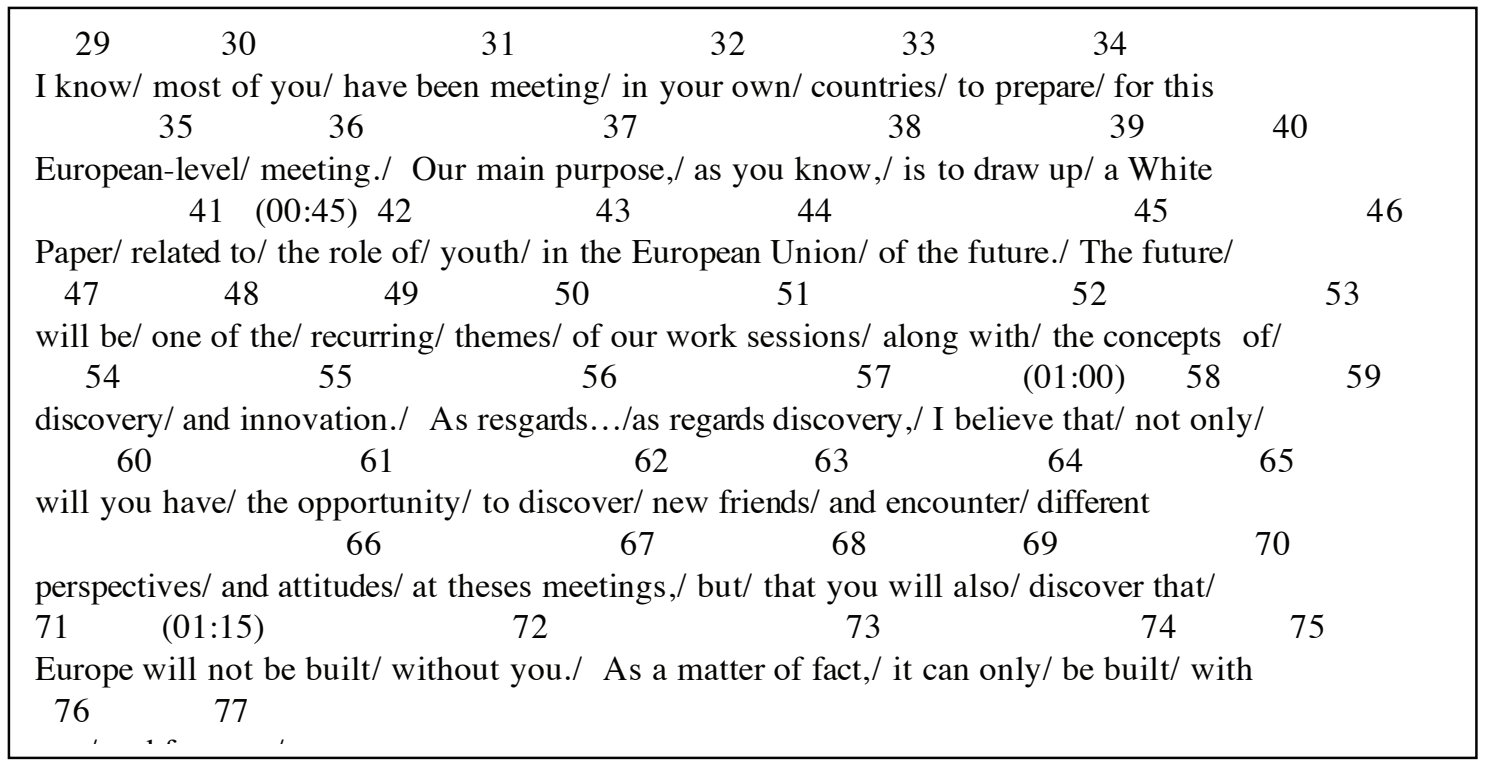

Figure 2. Source text with time codes and numbered "chunks"

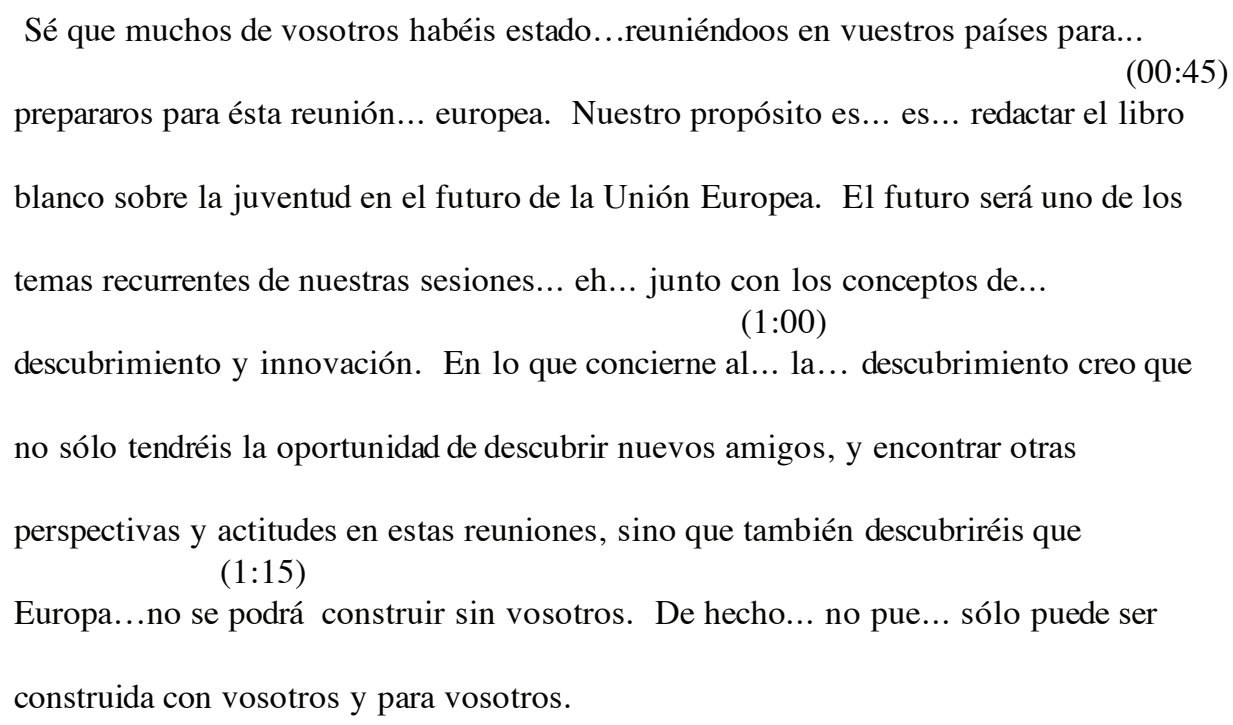

Figure 3. Target text with time codes

\section{Coding}

Each TT rendering was evaluated in terms of two factors: the extent to which the message is conserved with respect to meaning, rhetorical value, and clarity and the mechanics by which deviations from the ST occur. These observations are recorded as a binomial code, in which the first letter refers to content and the second refers to mechanics. For the purposes of this study, meaning, rhetorical value, and clarity are delineated as follows: 
- Meaning (M) refers to denotative meaning or propositional content and the extent to which it is altered or diminished.

- Rhetorical value $(\mathbf{R})$ refers to persuasive devices, emphasis, and pragmatic considerations, such as politeness and register and the extent to which they are approximated in the TT.

- Clarity (C) refers to issues of coherency, clarity, precision, and the extent to which the TT receiver must apply additional decoding effort to comprehend the message.

The mechanics by which deviations from the ST occur are delineated below:

- Omission (O) refers to any information present in the ST which is not rendered in the TT.

- Addition (A) refers to any information which is not found in the ST, but which appears in the

TT.

- Lexical shift (L) refers to alteration of some aspect of the ST message through word choice.

- Grammatical shift $(\mathbf{G})$ refers to alteration of the ST message through grammatical means, including: conjugation, gender, number, and parts of speech.

- Syntactical shift (S) refers to deviations from target language syntactical norms or which alter some aspect of the ST message.

- Coherency $(\mathbf{C})$ refers to hesitations, false-starts, and any disfluency which disrupts the flow of information.

- Pronunciation error $(\mathbf{P})$ refers to terms which are enunciated such that they are difficult to comprehend or may be mistaken for another term. This category does not include non-native and regional accents.

- Unintelligible (U) refers to any utterance which cannot be understood, whether through interpreter error or through other means, such as background noise or technical failure.

\begin{tabular}{|c|c|c|c|c|c|c|c|c|}
\hline \multirow[b]{2}{*}{ INT } & \multicolumn{2}{|c|}{$\begin{array}{l}\mathbf{4 2} \\
\text { white paper related } \\
\text { to }\end{array}$} & \multirow{2}{*}{$\begin{array}{l}\text { the role } \\
\text { of }\end{array}$} & \multirow{2}{*}{$\begin{array}{l}43 \\
\text { youth } \\
43 \\
\end{array}$} & \multicolumn{2}{|c|}{$\begin{array}{l}44 \\
\text { in the European } \\
\text { Union }\end{array}$} & \multicolumn{2}{|c|}{45} \\
\hline & 40 & 41 & & & 44 & & 45 & \\
\hline 1 & $\mathrm{~L}$ & $L$ & $\mathrm{MO}$ & 0 & & $\mathrm{MO}$ & & MO \\
\hline 2 & & & $\mathrm{MO}$ & & & & & $\mathrm{RS}$ \\
\hline 3 & & $\mathrm{~L}$ & $\mathrm{ML}$ & 0 & & $\mathrm{ML}$ & & RS \\
\hline 4 & & & MO & & & RO & & $C C$ \\
\hline 5 & $\mathrm{~L}$ & & MO & & $L$ & $\mathrm{RO}$ & & $\mathrm{MO}$ \\
\hline 6 & & & $\mathrm{ML}$ & & $C$ & $\mathrm{MO}$ & & $\mathrm{MO}$ \\
\hline 7 & C & $L$ & $\mathrm{MO}$ & 0 & & $\mathrm{MO}$ & & $M L$ \\
\hline 8 & & C & MO & & C & & & \\
\hline 9 & $\mathrm{~L}$ & $\mathrm{~L}$ & $\mathrm{ML}$ & $\mathrm{L}$ & & $\mathrm{ML}$ & $L$ & $\mathrm{CC}$ \\
\hline 10 & & $\mathrm{~L}$ & $\mathrm{MO}$ & 0 & & & & \\
\hline
\end{tabular}

Figure 4. Spreadsheet of coded observations (partial) 


42 the role of
\begin{tabular}{|l|l|l|l|l|l|l|l|l|l|l|l|l|l|}
\hline MO & $\mathbf{2 5}$ & RO & CO & & MO & $\mathbf{2 1}$ & RO & $\mathbf{3}$ & CO & & \\
\hline ML & $\mathbf{1 2}$ & RL & & CL & & & ML & $\mathbf{4}$ & RL & & CL & & \\
\hline MG & & RG & & CG & & & MG & & RG & & CG & & \\
\hline MC & & RC & & CC & & & MC & & RC & & CC & $\mathbf{1}$ & \\
\hline MS & & RS & & CS & & & MS & & RS & & CS & & \\
\hline MP & & RP & CP & & MP & RP & CP & & \\
\hline MU & & RU & CU & & & MU & & RU & & CU & & \\
\hline MA & RA & CA & & MA & & RA & & CA & & \\
\hline
\end{tabular}

Figure 5. Sample observation tables (over $75 \%$ coincidence of shifts)

\begin{tabular}{|c|c|}
\hline $\mathrm{ST}$ & $\begin{array}{l}\text { (Our main purpose, as you know, is to draw up a) White Paper related to the } \\
\text { role of youth in the European Union of the future }\end{array}$ \\
\hline TT 1 & la carta blanca.. \\
\hline TT 2 & - la juventud en el futuro de la Unión Europea. \\
\hline TT 3 & futuro de la comunidad europea. \\
\hline TT 4 & $\begin{array}{l}\text { un libro blanco, relacionada... eh... con _ la juventud del futuro... de la } \\
\text { Europa del futuro. }\end{array}$ \\
\hline TT 5 & un libro... en lo que refiere a la... eh... juventud de ___Europa \\
\hline TT 6 & un... un libro... blanco sobre la... política juvenil en ... en __ Europa \\
\hline TT 7 & el papel... el libro blanco...... de...eh... \\
\hline TT 8 & $\begin{array}{l}\text { un papel blanco para la _juventud para la... de la Unión Europeo en el } \\
\text { futuro. }\end{array}$ \\
\hline TT 9 & Con... lo primero, que me gustaría saber es... en... en... en el futuro. \\
\hline TT 10 & eh... un libro blanco para ___ la Unión Europea del futuro.... \\
\hline
\end{tabular}

Figure 6. Sample of ST and TT rendering excerpts

Statistical theory cautions against false readings which result from small sample sizes. Therefore, only ST terms which indicate that $75 \%$ or more of the student interpreters experienced some sort of difficulty were used as "units for analysis" or the focus of close scrutiny in this study and recorded using the binomial code. Other errors are nonetheless considered and are coded with reference to only the mechanics by which the message may have been altered. This helps to avoid visual clutter, and at the same time allows for observations to be noted and easily located for future examinations of the corpus.

\section{Sample analysis}

In the above example, twenty-five student interpreters omitted the term "role" such that the meaning of the ST utterance was altered or diminished, so the code MO is applied: (meaning altered through omission). That term is important to the message in that it specifies the relationship of youth to the conference's goals. In TT 2 and TT 3, the imagery of "the European Union of the future" is diminished by syntactic restructuring which results in "European Union" modifying "future": "el futuro de la Unión Europea" (future of the European Union) and "el futuro de la 
comunidad europea" (the future of the European Community), respectively. This does not substantially change the denotative meaning of the ST utterance, but alters the rhetorical structure, so the code RS is applied. TT 3 also refers to the European Community, rather than the European Union. Because these are not identical political bodies, the code ML is applied. In TT 3, "role" is rendered as mejor (better), a clear departure from the ST. In TT 6, the term is rendered as $l a$ politica (policy), which conveys part, but not all of the same meaning as the ST term; in both cases, the code ML (meaning altered through lexical shift). TT 4 contains a self-correction of the term futuro and is coded CC, indicating that clarity suffered through disfluency. TT 9 bears little or no relation to the ST, except for the term "future," so the code ML is applied.

The spreadsheet provides a visual representation of two useful pieces of information: the terms which are most difficult or problematic for the interpreters and which interpreters encounter difficulty most frequently. Seeing the number of notations below the word "role" it is clear that the term caused problems for many interpreters. Looking at TT 2 in the spreadsheet, one sees that only the term "role" has been altered or eliminated and a rhetorical device is diminished, but the message, by and large, is conveyed. By comparison, TT 9 alters the message considerably and clearly indicates a struggle to produce coherent speech. That contrast is evident in the spreadsheet.

Space does not permit in depth analysis here of even this small portion of the corpus, much less the full 80,000 word parallel corpus. In examining all forty renderings of Text 1, forty-eight words or phrases were identified on which at least $75 \%$ of the student interpreters demonstrated difficulty, meeting the standard for closer examination as "units for analysis". Text two contained thirty-five such items. This resulted in 1,920 possible renderings for units for analysis in Text 1 and 1,400 for Text 2. Some of the key findings of this analysis are given below.

\section{Findings}

Among the most striking outcomes of this study was the finding that the participants in produced fewer errors related to meaning and rhetorical value when interpreting into their non-native language (L2) than when interpreting into their native tongue (L1). Target renderings of Text 1 (English to Spanish) contained 16\% more errors and shifts of meaning and 7\% more shifts and errors of rhetorical effect than the renderings of Text 2 (Spanish to English). Not surprisingly, errors and shifts affecting clarity and receiver effort were $23 \%$ higher when rendering from L1 to L2.

\section{L2 to L1}

Many of the shifts of meaning and rhetorical effect may be traced to poor comprehension of the ST, in some cases due to weak vocabulary or familiarity with speech patterns typical of the ST register (L2). Such errors include comprehension and manipulation of modal, phrasal and compound verbs and the passive voice. Other errors appear to result from different causes, such as problems of cognitive load management, inadequate lag times, susceptibility to linguistic interference, and excessive adherence to the formal aspects of the ST. The concentrations of errors following complex and/or abstract portions of text support Gile's and MacWhinney's theories of delayed and cascading errors resulting from cognitive load exceeding capacity. Gile (1997), MacWhinney (1997) A number of errors related to lexical asymmetry in which a single term exists in one language, but is expressed by two or more terms in another language, depending upon the context. For example, the term "question" appeared four times in Text 1. "Question" when used as a noun referring to interrogation may be rendered in Spanish as pregunta, but when used in reference to issues, as in "a question of right or wrong," the term cuestión is appropriate. The phonetic similarity of "question" and cuestión may have influenced some interpreters' word choice. In all four cases, "question" was used in reference to interrogation. First, the speaker indicated that she had a number of questions and then each question was announced with phrases like "and that leads us to my next question." Each time that the term appeared, at least four interpreters rendered it as cuestion (theme/issue) and the third time that the term appears, twelve interpreters render it as cuestión. In one case, it is rendered as pregunta en cuestión (question at issue), possibly as a hedge, but nonetheless altering the message. Similar problems were noted when the term "ask" 
appeared in the ST. In Spanish, the verb "to ask" is rendered as preguntar when it refers to asking a question and pedir is used when making a request. In unit 79 of the ST, only nine interpreters correctly rendered the term as some form of pedir. In some cases, the request was rendered as a command, altering the rhetorical value of a softened request. This suggests a lack of facility or awareness of the pragmatics and/or vocabulary typical of this type of speech and the register in which it is delivered. Other difficulties related to pragmatics were evident in portions of Text 1 in which the speaker offered congratulations, reassurances, and hedged denials. Taken together, these observations suggest that instruction might profitably focus on the specialized language of public speaking, improving cognitive load management, increasing lag times, and teaching student interpreters to distance themselves from the formal or structural aspects of the ST.

Many of the inaccurate L2 to L1 renderings were well-formed and smoothly delivered. Well formed sentences often go unnoticed by the TT receiver who, presumably, does not possess full mastery of the ST language. Such errors, because they are smoothly delivered may also evade detection by instructors and go uncorrected. This phenomenon may contribute to the conventional wisdom dictating that interpreters, whenever possible, should work into their native language.

\section{L1 to L2}

Errors when working into the interpreters' non-native language fell largely into the categories of: syntactical shifts and restructuring difficulties, manipulation of phrasal, modal, and compound verbs, lexical asymmetry, and linguistic and phonetic interference. In Text 2, the speaker says, "pocas veces se ha pensado en" (lit: "few times/ it has been thought/ about," requiring modulation and/or syntactic restructuring and could be rendered as "little thought has been given to." Thirty-five of the student interpreters demonstrated difficulty with the phrase pocas veces and thirty-six showed difficulty with the passive form se ha pensado en. Compound verb problems appeared with the ST utterance, "a partir de este cambio, ha habido numerosos proyectos de integración" (since this change, there have been numerous integration projects). Thirty-one interpreters exhibited difficulty with the compound verb ha habido (have been). The verb phrase para poder seguir la clase (in order to be able to follow the class) proved problematic for thirtythree interpreters, twenty-five of whom omitted all or part of the utterance. These errors suggest that students would benefit from additional training and practice in L2 production so that syntactical manipulation and restructuring requires minimal conscious effort.

\section{L1 to $\mathrm{L} 2 / \mathrm{L} 2$ to $\mathrm{L} 1$}

Linguistic and phonetic interference were evident in both texts. The term "marginalization" appeared in Text 1 and its equivalent margincación appeared in Text 2. Regardless of interpreting direction, these terms produced TT renderings which strongly suggest "echoing" of the ST term. When rendering into Spanish, fourteen interpreters echoed the compound suffix -ization and only five self-corrected, suggesting that the remaining nine had not noticed the error. When rendering into Spanish, eleven interpreters truncated the term, rendering it as "marginate" or "margination," two said "marginalation", one said "marginalisize," and only two self-corrected. This suggests that, beyond simple echoing, there is uncertainty as to the correct form in English, again suggesting the need for register-specific language training. Nonsense echoing was noted when, for example, Text 1 mentions chicle (chewing gum) as part of a list of prohibitions for teachers of deaf students, which is rendered in one instance as "chicken gum." The interpreter seemed not to have noticed the error, moving blithely on. In Text 1, the term "committees" was rendered as comicios (elections) and "efforts" was rendered as ofertas (offers). Other examples of linguistic interference were complex: for example, one rendering of "efforts" was escuerzos (toads/weaklings), which is phonetically similar to the appropriate term esfuerzos (efforts). Also, the term "Dutch" (holandés) appears in Text 1; eleven interpreters rendered the term as alemán (German). "Dutch" sounds very much like deutsch (German for "German"), but that term does not exist in either Spanish or English. 


\section{Conclusion}

The MRC model devised for this study served the goals and criteria as set out above. Numerous examples of unexpected phenomena and patterns of interpreter behavior were noted, it is possible to navigate the corpus efficiently using the time codes, "chunk" numbers, words and word fragments. The spreadsheet offers a convenient visual reference for large amounts of data related to ST elements and to individual interpreter performances and areas of difficulty. This model does not dispense with all problems of subjectivity and analyst bias, but does mitigate those effects by offering a framework for analysis based on established standards and universal features of communication, rather than seeking examples of specific, predetermined phenomena. Subjectivity in making and recording observations is further reduced by establishing coding rules so that decisions are, at least, consistent. It is important to bear in mind that the sample size and population in this study limit the extent to which findings may be applied to other groups, most notably professional interpreters. Nonetheless, the MRC approach has been adapted as a teaching tool with results that support the general findings of the study. Dr. Cynthia Giambruno de Miguélez has applied the MRC approach for use in her interpreting classes at the Universidad de Alicante, in Spain. At this writing, that course is still in session, but preliminary findings are promising. The MRC approach was also adapted for use in a graduate-level translation course at the University of Arizona with very encouraging results.

Refinements to the methodology and expansion of the corpora will improve the reliability and validity of the MRC analytical approach. Areas for improvement include further refinement of the coding rules and the use of the spreadsheet software to capitalize on as-yet underutilized functions. Because the recordings which served as the basis for this corpus were made on analog equipment, tracks could not be time-aligned to the extent desired. However, the corpora are currently being expanded and the recent recordings have been made on digital equipment, making more precise time-alignment possible.

Future plans include closer examination of the correlation between lag times and comprehension related errors, a closer look at linguistic and phonetic interference, and efforts to develop a parallel corpus based on more experienced professional interpreters in order to begin to identify patterns of comportment among advanced practitioners.

\section{REFERENCES}

BIBER, D. (1998): Corpus Linguistics: Investigating Language Structure and Use, Cambridge, Cambridge University Press.

Collados Ais, Á. (1999) "Expectativas y evaluación de la calidad en interpretación de conferencias: revision de trabajos empíricos rrealizados hasta 1996”, Estudios Sobre Traducción E Interpretación 2, pp. 777-788.

GERVER, D. (1976): “Empirical Studies of Simultaneous Interpretation: A Review and a Model” In Brislin, R. (Ed.), Translation, Application and Research, New York, Gardner Press, pp. 165-207.

GILE, D. (1994): "Methodological Aspects of Interpretation and Translation Research", In Lambert, S. and B. Moser-Mercer (Eds.), Bridging the Gap: Empirical Research in Simultaneous Interpretation, Amsterdam, Benjamins, pp. 39-56.

GILE, D. (1997): “Conference Interpreting as a Cognitive Management Problem”. In G.M. Shreve, J.H. Danks, S.B. Fountain \& M.K. McBeath (Eds.), Cognitive Processes in Translation and Interpreting, Thousand Oaks, Sage, pp. 196-214.

Grice, P. H. (1975): "Logic and Conversation", in Syntax and Semantics 3, Speech Acts P. Cole and J.L. Morgan (Eds.), pp. 43-58.

KoPCZYNSKI, A. (1994): "Quality in Conference Interpreting: Some Pragmatic Problems”. In Lambert, S. and B. Moser-Mercer (Eds.) Bridging the Gap: Empirical Research in Simultaneous Interpretation, Amsterdam, Benjamins, pp. 87-100.

MaCWhinney, B. (1997): "Simultaneous Interpretatoin and the Competition Model”, In G.M. Shreve, J.H. Danks, S.B. Fountain \& M.K. McBeath (Eds.), Cognitive Processes in Translation and Interpreting, Thousand Oaks, Sage, pp. 215-233. 
Moser, B. (1977): “A Hypothetical Model and its Practical Application”, In Gerver, D \& H.W. Sinaiko, Language Interpretation and Communication, New York: Plenum, pp. 353-369.

Moser, B. (1997): “Beyond Curiosity: Can Interpreting Research Meet the Challenge?" In G.M. Shreve, J.H.

Danks, S.B. Fountain and M.K. McBeath (Eds.), Cognitive Processes in Translation and Interpreting, Thousand Oaks, Sage, pp. 176-195.

NeuberT, A. (1997): "Postulates for a Theory of Translatio", In G.M. Shreve, J.H. Danks, S.B. Fountain and M.K. McBeath (Eds.), Cognitive Processes in Translation and Interpreting, Thousand Oaks, Sage, pp. 1-24.

NiDA, E. (1964): Toward a Science of Translating, Leiden, Brill.

NiDA, E. (1976): “A Framework for the Analysis and Evaluation of Theories of Translation”, In Brislin, R. (Ed.), Translation, Application and Research, New York, Gardner Press, pp. 47-91.

REISS, K. and H. J. VERMEER (1984): Fundamentos para una teoría funcional de la tradución, Translation by Sandra García and Celia Martin.

SeArle, J. R. (1975): "Indirect Speech Acts", in Syntax and Semantics, vol 3, Speech Acts P. Cole and J.L. Morgan (Eds.), pp. 59-82.

Seleskovich, D. (1976): Interpretation, A Psychological Approach to Translating, In Brislin, R. (Ed.). Translation, Application and Research, New York, Gardner Press, pp. 47-91.

SHLESINGER, M. (1994): "Quality in Simultaneous Interpreting”, In Conference Interpreting: Current Trends in Research Proceedings of the International Conference on Interpreting: What do we know and how? Y. Gambier, D. Gile, D. Taylor, C. (Eds.) Amsterdam, Benjamins, pp.110- 122.

Sinclair, J. (1991): Corpus, Concordance, Collocation, Oxford, Oxford University Press.

StubBs, M. (1996): Text and Corpus Analysis, Oxford and Cambridge, Blackwell.

Toury, G. (1995): Descriptive Studies and Beyond, Amsterdam, Benjamins. 